\title{
Selenium Uptake by Edible Oyster Mushrooms (Pleurotus sp.) from Selenium-Hyperaccumulated Wheat Straw
}

\author{
Poonam BhatiA ${ }^{1}$, Ranjana PraKASH ${ }^{2}$ and N. Tejo PrAKASH ${ }^{1, *}$ \\ ${ }^{1}$ Department of Biotechnology and Environmental Sciences, and ${ }^{2}$ School of Chemistry and \\ Biochemistry, Thapar University, Patiala 147004, India
}

(Received July 30, 2012)

\begin{abstract}
Summary In an effort to produce selenium (Se)-fortifying edible mushrooms, five species of oyster mushroom (Pleurotus sp.), were cultivated on Se-rich wheat straw collected from a seleniferous belt of Punjab, India. Total selenium was analyzed in the selenium hyperaccumulated wheat straw and the fruiting bodies. Significantly high levels $(p<0.0001)$ of Se uptake were observed in fruiting bodies of all mushrooms grown on Se-rich wheat straw. To the best of our knowledge, accumulation and quantification of selenium in mushrooms has hitherto not been reported with substrates naturally enriched with selenium. The results demonstrate the potential of selenium-rich agricultural residues as substrates for production of Se-enriched mushrooms and the ability of different species of oyster mushrooms to absorb and fortify selenium. The study envisages potential use of selenium-rich agricultural residues towards cultivation of Se-enriched mushrooms for application in selenium supplementation or neutraceutical preparations.
\end{abstract}

Key Words selenium, uptake, wheat straw, Pleurotus

Historically, the image of selenium (Se) has changed dramatically over the last century. Initially, selenium was widely considered to be a toxic agent in mammals. It was first recognized to be an essential trace element in 1957 and has been shown to be active in glutathione peroxidase (GSH-Px) in red blood cells. Since its discovery about half a century ago, selenium has been a subject of intensive research. Selenium, an essential micronutrient with antioxidant properties, has received considerable attention for potential roles in cancer prevention for both human beings and animals (1). One of the first and best known examples of the physiological importance of Se is the family of selenium-dependent glutathione peroxidases, that protect membrane lipids and phospholipids from oxidative stress by catalyzing reduction of hydrogen peroxide, lipid and phospholipid hydroperoxide (2). The element also (a) seems active at supra-nutritional levels of dietary intake, mostly in the field of cancer prevention (3-6); (b) may possess pharmacological implications as an adjuvant treatment of some cancers (7); and (c) facilitates enhancement of intrinsic defenses against ROS (8). In humans, it is well recognized that selenium plays a crucial role in various physiological processes and its altered level has a direct impact on health leading to various disorders. The World Health Organization report advises a Se intake of $40 \mu \mathrm{g} / \mathrm{d}$ as the average intake level needed to ensure meeting normative requirements of healthy adults.

With increasing demand for nutritional food across the world, enrichment of staple diets with essential

\footnotetext{
*To whom correspondence should be addressed.

E-mail: ntejoprakash@thapar.edu
}

micronutrients such as Se has been gaining importance. Selenium deficiency is linked with various conditions such as increased cancer and infection risk, male infertility, decrease in immune and thyroid function, and several neurologic conditions, including Alzheimer's and Parkinson's disease (5) and increase in urinary ketone bodies in starved rats (9). The majority of the population across Scandinavia and other European countries is at risk of Se deficiency, because of which various supplementation strategies are being attempted, including naturally fortified dietary intake. Selenium deficiency can be significantly tackled by its supplementation through dietary sources (10). Different food sources of plant and animal origin are known to be potential dietary sources of selenium. The main dietary constituents providing selenium in the diet are bread, meat, fish, eggs, and milk/dairy products (11). Among the crop plants, wheat, maize, pulses and certain vegetables crops such as Allium sativum, broccoli, garlic and mushrooms are known to be good sources of selenium.

Mushrooms are interesting food items for the formulation of a healthy diet as they are devoid of high calories and fat but are rich in proteins, minerals and dietary fibre $(12,13)$. They have been extensively studied for their nutritional and medicinal properties. Mushrooms have known antioxidant properties provided by different compounds such as phenolics, ergothioneine and selenium (Se) (14-17). Natural mushrooms such as Boletus edulis for example, may have concentrations of up to $17 \mathrm{mg} \mathrm{Se} / \mathrm{kg} \mathrm{dw}$, while wild Agaricus sp. may contain $2.7 \mathrm{mg} \mathrm{Se} / \mathrm{kg} \mathrm{dw}$ and P. cornucopiae and Grifola frondosa may have less than $0.5 \mathrm{mg} \mathrm{Se} / \mathrm{kg} \mathrm{dw}(16,18)$. Selenium content in mushrooms is observably species 
specific (19). The main bioavailable species of selenium in Agaricus bisporus (20) and Lentinula edodes (21) cultivated on selenium-supplemented substrates was found to be selenomethioneine under conditions where exogenous supplementation of selenium was carried out using inorganic Se species, reports indicate an increase in the Se content in mycelia as well as fruiting bodies of mushrooms (15, 16, 22). Werner and Beelman (15) also demonstrated that Se accumulated in Agaricus bisporus when the substrate was supplemented with aqueous solutions of selenite at different concentrations and that the Se uptake by A. bisporus was linearly related to concentration in the compost.

In the present study, five different species of genus Pleurotus (Oyster mushroom) comprising commercially important edible as well as medicinal important species were considered. These species were cultivated on Se-rich wheat straw collected post-harvest from a seleniferous region of Punjab, India. Pleurotus mushrooms have high nutritional value and can be a good source of protein, carbohydrates, vitamins, calcium and iron (23). Reported health-related properties of these genera include reduction of cholesterol levels, antitumor, antiviral, antibacterial and immunomodulating activity (24).

The present study demonstrates the use selenium rich agricultural residues to cultivate different species of oyster mushrooms (Pleurotus sp.) and suggests the use of these residues as a prospective raw material for generating Se-fortified mushrooms.

\section{Materials and Methods}

Analytical grades of 2,3-diaminonaphthalene (DAN, Hi-Media) and cyclohexane (SD-Fine, India) were used in the study. Nitric $\left(\mathrm{HNO}_{3}\right)$, hydrochloric $(\mathrm{HCl})$ and perchloric $\left(\mathrm{HClO}_{4}\right)$ acids were procured from Merck, India.

The strains of Pleurotus djamor, P. sajorcaju, P. ostreatus, $P$. citrinopileatus and P. fossulatus were obtained from NRCM, Solan (Himachal Pradesh, India). All strains were cultured on potato dextrose agar (PDA) medium and stored at $4^{\circ} \mathrm{C}$ for further use. The selenium-rich agricultural residues of wheat harvested from a seleniferous belt $\left(32^{\circ} 46^{\prime} \mathrm{N}, 74^{\circ} 32^{\prime} \mathrm{E}\right)$ of Punjab, India, were used as substrates for mushroom cultivation. The test mushrooms were cultivated on agricultural residues collected from the test site, following the method outlined by Punjab Agricultural University (25) with minor modifications. Spawn was prepared on wheat grains and was used for seeding of Se-rich substrate. The wheat straw was treated with formalin for the purpose of disinfection. The straw was soaked overnight in water containing formalin (1.5\%). The disinfected straw was allowed to air dry before the inoculation of the substrate with the fungal spawn. After inoculation, the substrate was layered in polypropylene bags and kept in a cultivation chamber set at $25 \pm 4^{\circ} \mathrm{C}$. The moisture was maintained by spraying water over the culture bags twice a day. A similar procedure was followed to cultivate control mushrooms, with non-Se wheat straw as the substrate. On maturity (about $30 \mathrm{~d}$ after spawning), fruiting bod- ies were collected, by cutting the base of the stipe with sterile surgical blade, weighed and dried at $40^{\circ} \mathrm{C}$ in an oven for near complete dehydration. The dry samples were macerated using an agate mortar and pestle.

Selenium content in powdered samples was analysed using a fluorescence spectrometric method (26). In brief, a $100 \mathrm{mg}$ portion of the sample was weighed accurately in an acid-washed kjeldahl flask containing $5 \mathrm{~mL}$ concentrated nitric acid. After incubation for $30 \mathrm{~min}$ at room temperature, $2 \mathrm{~mL}$ of perchloric acid $(72 \%)$ was added and the sample was digested. The mixture was then allowed to cool to room temperature. To facilitate the reduction of selenate $\left(\mathrm{SeO}_{4}{ }^{2-}\right)$ to selenite $\left(\mathrm{SeO}_{3}{ }^{2-}\right), 2 \mathrm{~mL}$ of $1.0 \mathrm{~N} \mathrm{HCl}$ was added and the flask was placed in the water bath $\left(100^{\circ} \mathrm{C}\right)$ for $15 \mathrm{~min}$. The final volume of the digest was adjusted to $25 \mathrm{~mL}$ with $0.1 \mathrm{~N}$ $\mathrm{HCl}$. To $1.0 \mathrm{~mL}$ of the diluted digest, $200 \mu \mathrm{L}$ of $1: 1$ formic acid and $200 \mu \mathrm{L}$ of stabilizing solution [0.04 M $\mathrm{Na}_{2}$ EDTA containing 10\% hydroxylamine hydrochloride $\left.\left(\mathrm{NH}_{2} \mathrm{OH} \cdot \mathrm{HCl}\right)\right]$ were added. The final $\mathrm{pH}$ of the digest was adjusted to 1.8 with $\mathrm{NH}_{4} \mathrm{OH}$ and placed in a water bath at $50^{\circ} \mathrm{C}$ for $10 \mathrm{~min} .0 .5 \mathrm{~mL}$ DAN $(0.1 \%$ in $0.1 \mathrm{M} \mathrm{HCl}$ ) was added to the reaction mixture, shaken thoroughly (20 s) and kept in the water bath at $50^{\circ} \mathrm{C}$ for $30 \mathrm{~min}$. After cooling to room temperature, $2 \mathrm{~mL}$ of cyclohexane were added, and the contents were vigorously mixed, and allowed to separate. The separated cyclohexane layer was washed with $5 \mathrm{~mL} 0.1 \mathrm{~N} \mathrm{HCl}$. The emission spectrum of piazselenol complex formed during the reaction was measured using a fluorescence spectrometer (Perkin Elmer LS-45) at excitation and emission wavelengths of 320 and $520 \mathrm{~nm}$ respectively. Se quantification in each sample was carried out by the relative method using emission spectrum of NIST certified Selenium ICP standard solution (SRM-1349).

\section{Results and Discussion}

The study presents the observations on uptake and accumulation of Se among different species of Pleurotus cultivated using wheat straw naturally enriched with Se as the substrate. Different species of Pleurotus genus were examined for their potential to take up and accumulate Se. Selenium concentration in wheat straw used as growth substrate and in fruiting bodies of different mushrooms is shown in Table 1. Mushrooms cultivated on naturally Se-enriched substrates did not differ from controls in terms of yield (expressed as fresh mushroom weight per bag) or production length (number of days elapsed from inoculation to harvest).

The selenium concentration in unenriched substrate was found to be higher $(1.9 \pm 0.8 \mu \mathrm{g} \mathrm{Se} / \mathrm{g} \mathrm{dw})$ than in the earlier reports which lay in the range of $0.09-0.19 \mu \mathrm{g}$ $\mathrm{Se} / \mathrm{g} \mathrm{dw}$ in different substrates $(27,28)$ and the resulting concentrations in fruiting bodies were in the range of $2.9-5.2 \mu \mathrm{g} \mathrm{Se} / \mathrm{g} \mathrm{dw}$, which is almost comparable to the range (0.12-3.4 $\mu \mathrm{g} \mathrm{Se} / \mathrm{g} \mathrm{dw})$ of selenium conentartion in wild and edible species of Pleurotus (29-31). The fruiting bodies (first flush) of all species of Pleurotus harvested from Se-rich wheat straw containing a total Se concentration of $24.0 \pm 0.2 \mu \mathrm{g} \mathrm{Se} / \mathrm{g} \mathrm{dw}$, were noted to 
Table 1. Total selenium levels in substrate and different species of Selenium-enriched/control mushrooms.

Total selenium $(\mu \mathrm{g} / \mathrm{g} \mathrm{dw})$

\begin{tabular}{|c|c|c|c|c|c|c|}
\hline \multirow[t]{2}{*}{ Sample } & \multirow{2}{*}{ Straw } & \multicolumn{5}{|c|}{ Mushroom } \\
\hline & & P. djamor & P. ostreatus & P. sajorcaju & P. fossulatus & P. citrinopileatus \\
\hline $\mathrm{Se}$ & $24.0 \pm 0.2$ & $145.4 \pm 2.9$ & $44.3 \pm 2.3$ & $43.5 \pm 2.1$ & $37.2 \pm 0.6$ & $26.1 \pm 2.8$ \\
\hline Control (Non-Se) & $1.9 \pm 0.8$ & $5.0 \pm 0.5$ & $3.4 \pm 0.1$ & $5.2 \pm 1.0$ & $3.5 \pm 0.5$ & $2.9 \pm 0.14$ \\
\hline
\end{tabular}

Values are presented as mean $\pm \operatorname{SD}(n=3)$.

accumulate significantly higher $(p<0.0001)$ selenium as compared to control mushrooms grown on control wheat straw (1.9 $\pm 0.8 \mu \mathrm{g} \mathrm{Se} / \mathrm{g} \mathrm{dw})$.

Among the five strains of Pleurotus, P. djamor was found to accumulate significantly high levels of Se (expressed as $\mu \mathrm{g} \mathrm{Se} / \mathrm{g} \mathrm{dw}$ ) as compared to control samples i.e. $145.4 \pm 2.9$ vs $5.0 \pm 0.46$, followed by $P$. ostreatus, $P$. sajorcaju, P. fossulatus and P. citrinopileatus (Table 1). The extent of accumulation was higher than the selenium concentration reported in the case of Pleurotus eryngii (4.6 and $9.3 \mu \mathrm{g} \mathrm{Se} / \mathrm{g} \mathrm{dw}$ ) cultivated on substrates supplemented with 5.0 and $10.0 \mu \mathrm{g} \mathrm{Se} / \mathrm{g}$ dw of sodium selenite respectively (32), Similar results have recently been reported by da Silva et al. (27), where selenium accumulation in P. ostreatus was found to be higher $(57.6 \mu \mathrm{g}$ $\mathrm{Se} / \mathrm{g} \mathrm{dw})$ than our observations (44.3 $\mu \mathrm{g} \mathrm{Se} / \mathrm{g} \mathrm{dw})$ with the same species when cultivated on Se-enriched coffee husks supplemented with $3.2 \mathrm{mg} / \mathrm{kg}$ of sodium selenite. Total selenium content in enriched L. edodes and Ganoderma lucidium was found to be $46 \mu \mathrm{g} \mathrm{Se} / \mathrm{g}$ and $72 \mu \mathrm{g}$ $\mathrm{Se} / \mathrm{g}$ respectively $(33,34)$, which lies within the range observed in the present study. The observations clearly demonstrated that the tolerance and uptake of selenium by various species of mushrooms are dependent upon the variety of mushroom species as well as the form of selenium supplementation.

Although investigations have been carried on $\mathrm{Se}$ uptake and activity of Se-enriched mushrooms, by other researchers, on substrates supplemented with inorganic selenium compounds $(30,35)$ such as selenite, to the best of our knowledge, there is no information on Se levels in mushroom grown on substrates naturally enriched with selenium. As absorption of Se in the body depends on its bioavailability and speciation, with the organic species being effectively bioavailable (4), it is important to examine the extent of uptake of Se from substrates that have significantly high levels of organo-selenium complexes (36). Substrates, such as wheat straw, naturally enriched with selenium have organo-selenium species that are envisaged to have potential physiological and pharmacological benefits (36). Further, preliminary findings on mushrooms cultivated on substrates naturally enriched with Se were the significantly high levels of SeMet when compared to controls (data not shown). In this context, it is important to note that Se-rich mushrooms have been effective in retarding chemically induced tumors when fed to mice $(37,38)$. Keeping this in view, mushrooms fortified/enriched in Se from natural sources might possess significant levels of bioaccessible forms of selenium, thus facilitating enhanced bioavailability and bioaccessibility of selenium required at therapeutic or neutraceutical levels, through diet.

The present study, thus, proposes the use of Se-rich agricultural residues as substrates for mushroom cultivation for human and livestock supplementation.

\section{Acknowledgments}

Research grants under UGC-SAP (II) to Dr. Tejo Prakash and RGNF-UGC to Poonam Bhatia are duly acknowledged.

\section{REFERENCES}

1) Berry MJ. 2005. Insights into the hierarchy of selenium incorporation. Nature 37: 1162-1163.

2) Brigelius-Flohe R. 2006. Glutathione peroxidases and redox-regulated transcription factors. Biol Chem 387: 1329-1335.

3) Finley JW, Davis C, Feng Y. 2000. Selenium from highselenium broccoli is protective against colon cancer in rats. J Nutr 130: 2384-2389.

4) Finley W. 2006. Bioavailability of selenium from foods. Nutr Rev 64: 146-151.

5) Rayman MP. 2000. The importance of selenium to human health. Lancet 356: 233-241.

6) Rayman MP. 2005. Selenium in cancer prevention: A review of the evidence and mechanism of action. Proc Nutr Soc 64: 527-542.

7) Himeno S, Imura H. 2000. New aspects of physiological and pharmacological roles of selenium. J Health Sci 46: 393-398.

8) Zhou X, Ji WJ, Zhu Y, Li H, Huang TG, Li YM. 2007. Enhancement of endogenous defenses against ROS by supra-nutritional level of selenium is more safe and effective than antioxidant supplementation in reducing hypertensive target organ damage. Med Hypotheses $\mathbf{6 8}$ : 952-956.

9) Yoshida M. 1991. Effect of selenium deficiency on urinary ketone body excretion in starved rats. J Nutr Sci Vitaminol 37: 425-434.

10) Ximenez-Embun P, Alonso I, Madrid-Albarran Y, Camara C. 2004. Establishment of selenium uptake and species distribution in lupin, Indian mustard and sunflower plants. J Agric Food Chem 52: 832-838.

11) Fairweather-Tait JS, Bao Y, Broadley RM, Collings R, Ford D, Hesbeth DJ, Hurst R. 2011. Selenium in human health and disease. Antioxid Redox Signal 14: 1337-1383. 
12) Manzi P, Gambelli L, Marconi S, Vivanti V, Pizzoferrato L. 1999. Nutrients in edible mushrooms: an inter-species comparative study. Food Chem 65: 477-482.

13) Manzi P, Pizzaferrato L. 2000. $\beta$ glucans in edible mushrooms. Food Chem 68: 315-318.

14) Mau JL, Lin HC, Song SF. 2002. Antioxidant properties of several specialty mushrooms. Food Res Int 35: 519-526.

15) Werner AW, Beelman RB. 2002. Growing high selenium edible and medicinal mushroom (Agaricus bisporus (J. Lge) Imbach) as ingredients for functional food or dietary supplements. Int J Med Mush 4: 167-171.

16) Beelman RB, Royse DJ. 2006. Selenium enrichment of Pleurotus cornucopiae (Paulet) and Grifola frondosa (Dicks.: Fr.) S.F. gray mushrooms. Int J Med Mush 8: 1-8.

17) Dubost NJ, Beelman RB, Royse DJ. 2007. Influence of selected cultural factors and postharvest storage on ergothioneine content of common button mushroom Agaricus bisporus (J. Lge) Imbach (Agaricomycetideae). Int J Med Mush 9: 163-176.

18) Piepponen S, Liukkonen-Lilja H, Kuusi T. 1983. The selenium content of edible mushrooms in Finland. Z Lebensm Unters Forsch 177: 257-260.

19) Stijve T. 1977. Selenium content of mushrooms. Z Lebensm Unters Forsch 164: 201-203.

20) Diaz Huerta V, Sanchez MLF, Sanz-Medel A. 2006. An attempt to differentiate HPLC ICP-MS selenium speciation in natural and selenised Agaricus mushroom using different species extraction procedures. Anal Bioanal Chem 384: 902-907.

21) Yoshida M, Sugihara S, Inoue Y, Chihara Y, Kondô M, Miyamoto S, Sukcharoen B. 2005. Composition of chemical species of selenium contained in seleniumenriched shiitake mushroom and vegetables determined by high performance liquid chromatography with inductively coupled plasma mass spectrometry. J Nutr Sci Vitaminol 51: 194-199.

22) Stajic M, Sikorski J, Wasser SP, Nevo E. 2005. Genetic similarity and taxonomic relationships within the genus Pleurotus (higher Basidiomycetes) determined by RAPD analysis. Mycotaxon 93: 247-255.

23) Schmidt P, Welscher FS, Nascimento J, Junior FMV. 2003. Pretreatment effects on fiber degradation of brachiaria hay by Pleurotus ostreatus fungus. Revista brasiliena de Zootecnia 32: 1866-1871.

24) Sarangi I, Ghosh D, Bhutia SK, Mallick SK, Maiti TK. 2006. Anti-tumour immunomodulating effects of Pleurotus ostreatus mycelia-derived proteoglycans. Int Immunopharmacol 6: 1287-1297.

25) Khanna PK. 2003. Mushroom growing. In: Mushroom Cultivation (Singh AP, eds), p 1-60. Punjab Agricultural University Press, Ludhiana.

26) Levesque M, Vendette ED. 1970. Selenium determina- tion in soil and plant materials. Can J Soil Sci 51: 85-93.

27) da Silva MCS, Naozuka J, da Luz JMR, de Assuncao LS, Oliveira PV, Vanetti MCD, Bazzolli DMS, Kasuya MCM. 2012. Enrichment of Pleurotus ostreatus mushrooms with selenium in coffee husks. Food Chem 131: $558-563$.

28) Lee CY, Park JE, Kim BB, Kim SM, Ro HS. 2009. Determination of mineral components in the cultivation substrates of edible mushrooms and their uptake into fruiting bodies. Mycobiology 37: 109-113.

29) Andersen ALSE, Lange M, Bech K. 1982. Trace elements in edible mushrooms. Stat Levnedsmiddelinst Publ 68: 29.

30) Costa-Silva F, Marques G, Matos CC, Barros AIRNA, Nunes FM. 2011. Selenium contents of Portuguese commercial and wild edible mushrooms. Food Chem 126: 91-96.

31) Vetter J, Hajdu C, Gyorfi J, Maszlaver P. 2005. Mineral composition of the cultivated mushrooms Agaricus bisporus, Pleurotus ostreatus and Lentinula edodes. Acta Alimentaria 34: 441-451.

32) Estrada AER, Lee HJ, Beelman RB, Jimenez-Gasco MD, Royse DJ. 2009. Enhancement of the antioxidants ergothioneine and selenium in Pleurotus eryngii var. eryngii basidiomata through cultural practices. World J Microbiol Biotechnol 25: 1597-1607.

33) Gergely V, Kubachka KM, Mounicou S, Fodor P, Caruso JA. 2006. Selenium speciation in Agaricus bisporus and Lentinula edodes mushroom proteins using multidimensional chromatography coupled to inductively coupled plasma mass spectrometry. J Chromatogr A 1101: 94-102.

34) Falandysz J. 2008. Selenium in edible mushrooms. J Environ Sci Health C 26: 256-299.

35) Clark LC, Combs GF Jr, Turnbull BW, Slate EH, Slate DK, Chalker CJ, Davis LS, Glover RA, Graham GF, Gross EG, Krongrad A, Lesher JL Jr, Park H, Sander BB Jr, Smith CL, Taylor JR. 1996. Effect of Se supplementation for cancer prevention in patient with carcinoma of the skin. A randomized controlled trial. J Am Med Assoc 276: 1957-1963.

36) Cubadda F, Aureli F, Ciardullo S, D'Amato M, Raggi A, Acharya R, Reddy AVR, Tejo Prakash N. 2010. Changes in selenium speciation as associated with increase in tissue concentrations of selenium in wheat grain. J Agric Food Chem 58: 2295-2301.

37) Spolar MR, Schaffer EM, Beelman RB, Milner JA. 1999. Selenium-enriched Agaricus bisporus mushrooms suppress 7,12-dimethylbenz(a)anthracene bioactivation in mammary tissue. Cancer Lett 138: 145-150.

38) Che C, Yingmei Z, Yanchao L, Huiyuan C, Yaming Z. 2007. In vivo and in vitro anti-tumour response of selenium-protein polysaccharide extracted from rich selenium Agaricus blazei. Food Agric Immunol 18: 139-149. 